\title{
Green Building Business is Booming
}

\section{Rich Snow* and Mary Snow}

Applied Aviation Sciences, Embry-Riddle Aeronautical University, Daytona Beach, Florida, USA

Shelter is one of life's basic necessities. However, according to the U.S. Department of Energy, residential and commercial buildings account for nearly $40 \%$ of the total carbon dioxide $\left(\mathrm{CO}_{2}\right)$ released in the United States annually [1]. The percentage is even higher in China, which leads the world in $\mathrm{CO}_{2}$ emissions from buildings. Most of this $\mathrm{CO}_{2}$ comes from burning fossil fuels to provide the energy necessary to cool, heat, and light homes, office buildings, and retail space. $\mathrm{CO}_{2}$ emissions from residential and commercials buildings are forecast to increase more than emissions from any other sector over the next 25 years. This added output of greenhouse gas emissions certainly will have an adverse impact on the climate. However, this need not be the case.

Numerous people in developing countries use whatever natural resources are at hand to create housing that minimizes, or even benefits from, local climate conditions. In desert regions of the tropics and subtropics, high temperatures and high sun angles cause the days to be hot. Conversely, at night, deserts can be quite cold. With little vegetation and with predominately high pressure in the subtropical deserts, precipitation and humidity levels are usually low, so they do not tend to be a factor in shelter building design. However, to address both the diurnal as well as seasonal temperature variations, there has been a wide use of natural materials such as straw and mud, which are combined to create adobe. The homes and other buildings, therefore, have a high heat capacity. With little rain, roofs are generally flat and often provide suitable terraces during the evenings. Windows are typically small and inset to keep out the solar heat during the day as well as the cold at night. The houses are arranged closely with narrow streets to maximize the shade created by the neighboring houses, as can be seen in many communities of the Middle East.

In the hotter and wetter regions of the tropics, the climate also is characterized by high sun angle, yet there are higher rainfall amounts, higher humidity, and little variation in diurnal or seasonal temperatures. Shelters there must be well-ventilated, provide adequate shade, and have roofs that are water resistant. The neighboring jungles with their abundant vegetation provide various vines, fronds, and support poles, such as bamboo. These natural forest products allow for the construction of simple houses with pitched, over-hanging rooftops on stilted frames that allow optimal air-flow underneath and within while eluding dangerous creatures on the ground and flood waters.

Perhaps the best example of shelter with minimal environmental impact using abundant local resources is the igloo, although they are rarely seen today. The igloo is constructed of blocks of relatively dry and compacted snow arranged in a hemispheric shape to minimize its exterior exposure to wind and cold. They are capable of withstanding the brutally cold winds of the Arctic winter. Due to their low conductivity, the snow blocks allow an igloo to maintain temperatures as high as $15^{\circ} \mathrm{C}$ while the outside air is well below freezing. The creativity and comprehension of the surrounding environment among our ancestors and the technologically less developed people of today has given rise to dwellings of amazing diversity from the sod-roofed dugouts of the pioneers living on the North American prairies to the portable yurts of the nomadic tribes of Asia.

The igloo and the adobe are well-suited to their local climates and illustrate the use of natural construction materials under very different environmental conditions. Today, modern houses and other structures tend to make use of manufactured building materials that are shipped great distances. These prefabricated materials typically disregard the proximity and natural attributes of particular substances, and rely instead on materials that can be harvested or produced on a massive scale, such as wood or concrete. Cement production is also a major contributor to $\mathrm{CO}_{2}$ emissions. Ignoring local climate, construction often proceeds at a breakneck pace based on the notion that with enormous inputs of fossil fuel derived energy to power heating and cooling systems, electrical needs, and lighting, most external conditions can be disregarded. As a result, houses, offices, and entire cities are built with little regard of environmental circumstances.

Rural landscapes have been increasingly transformed into sprawling suburbs located many miles from city centers and workplaces adding to the carbon overloading of the atmosphere through driving long distances to and from work. The waste heat generated through air conditioning systems and automobile engines, along with the use of concrete and asphalt has helped create the urban heat island effect which contributes to global warming. The urban heat island effect changes not only temperature, but every aspect of local weather. Storm water systems remove water from the largely impermeable surface resulting in cities that become hydrologic deserts. There is less natural evaporative cooling from rain water when it is carried away quickly through city storm water drains. The natural recharging of aquifers that supply fresh water is also diminished by the impermeable surfaces. Wind speed and direction are altered by skyscrapers and coastlines cluttered with condominiums. However, by applying a few simple principles regarding building materials, climate, and the environment, construction can occur that maximizes materials and space while creating healthier and more productive places to work and to live.

For example, in the hotter and wetter climates of the tropics and other locations with high summer temperatures, wind can be exploited as a natural form of air conditioning ushering in both lower temperatures and humidity. In climates where external conditions are not extreme, ventilation is of considerable significance for the average home. Proper ventilation can maintain indoor temperatures that are very near those outside by removing heat generated internally. Very effective in this regard is cross-ventilation, which uses the natural effect of the pressure differentiation that generates wind in relation to a building's facades. On a hillside, there is a diurnal reversal of wind generated through the low pressure that develops on the solar heated

${ }^{*}$ Corresponding author: Richard Snow, PhD, Professor of Applied Aviation Sciences, Embry-Riddle Aeronautical University, Daytona Beach, Florida, USA, Tel: 386226 7104; E-mail: snow4fc@erau.edu

Received August 17, 2017; Accepted August 21, 2017; Published August 25 2017

Citation: Snow R, Snow M (2017) Green Building Business is Booming. J Climatol Weather Forecasting 5: e112. doi:10.4172/2332-2594.1000e112

Copyright: (c) 2017 Snow R, et al. This is an open-access article distributed under the terms of the Creative Commons Attribution License, which permits unrestricted use, distribution, and reproduction in any medium, provided the original author and source are credited. 
slope during the day. The heating of the slope causes air molecules to collide with greater force and frequency and spread apart. This less dense air then rises and cooler air that had pooled in the valley is drawn upwards to replace it. At night the system is reversed. As the hillslope cools rapidly under the night sky, air molecules gather closely together, and the resultant denser air drains down the slope. A pair of windows on the upslope and downslope sides of a building will take advantage of this upslope, or valley breeze, in the day time, and the downslope, or mountain breeze, at night. Similarly, a coastal location can build in such a way that maximizes the use of the sea breeze during the day, and the less pronounced land breeze that occurs at night.

In colder climates, local topography also plays a significant role. High winds frequently occur on the windward side of slopes in higher latitudes. If such situations are factored into building design, then windbreaks in the form of rows of vegetation can be planted on the windward side. The channeling of wind through valleys increases wind speed and requires special design. The local building response to the cold mistral winds of the Rhone Valley provides a good example. Small windows or even no windows at all, are characteristic of the northwardfacing sides of buildings found there.

Today, construction companies and their CEOs are rediscovering the personal and economic benefits in designing with nature. Leadership in Energy and Environmental Design (LEED) is a certification system for designing and constructing green buildings and neighborhoods [2]. When a building dons a LEED's certification plaque, its occupants are assured that independent verification has been awarded based on design, construction materials, waste reduction, and resource efficiency as well as operation and management resulting in healthy and costeffective buildings. Certification involves most types of buildings through all phases of development, from already existing buildings to new construction, from houses to hospitals, and from offices to neighborhoods. LEED has been instrumental in advancing the green building industry. The process is open and transparent, consensusbased, and involves numerous rounds of public input as well as approval from the U.S. Green Building Council. LEED ensures that innovators require more from buildings, including healthy and more productive experiences along with the conservation of valuable resources while benefitting the bottom line.

The process of earning LEED certification is based on acquiring points across the following nine essential aspects of green buildings: integrative process; location and transportation; sustainable sites; water efficiency; energy and atmosphere; materials and resources; indoor environmental quality; innovation; and regional priority. By constructing healthier buildings, whether it is a home, office, or multi-family building, the results are multiple benefits for people and the planet. With decreased utility costs and higher lease rates, LEED buildings reduce stress on the environment through energy efficiency and resource conservation while achieving profits for property owners. With accelerating climate change, green building design is more important than ever in time and space, which explains why LEED has gone global. Currently, there are more than 79,000 projects participating in LEED in 160 countries and territories spread over 15 billion square feet [2].

To curtail the worst effects of climate change, humankind needs to act quickly to slow, stop, and eventually reverse emissions of greenhouse gases. The building sector plays a significant role in reducing the impacts associated with global warming by transforming houses, stores, and offices and neighborhoods into climate-friendly, resource conserving, energy-efficient entities. The Intergovernmental Panel on Climate Change (IPCC) predicts that by the end of this century, $\mathrm{CO}_{2}$ and other greenhouse gas emissions from human activities will raise global temperatures by an additional 1.5 to $6^{\circ}$ Celsius [3]. The high end scenario is based on doing nothing to curtail climate change, or conducting business as usual. The impacts of additional warming include altering patterns of jet streams and thereby, changing the general circulation of the atmosphere and ocean. This change also alters the precipitation patterns to which humans have adapted, and have built infrastructure to accommodate. The added heat energy to Earth's climate system, which has varied only $1^{\circ}$ Celsius since civilization began, will continue to cause more frequent and severe flooding, more frequent and prolonged droughts, longer and more widespread forest fire seasons, lower crop yields, fresh water shortages, rising sea levels, ocean acidification and the breakdown of the marine food chain, the death of coral reefs, the displacement of millions of people along the coasts, and the spread of infectious diseases. Dealing with these problems requires a significant change in how humans generate and use energy. Fortunately, the technology to make substantial reductions in energy use and $\mathrm{CO}_{2}$ emissions already exists. One of the most significant contributions for combating the challenge of climate change is through green building design and construction, and in this sector, business is booming.

\section{References}

1. US Department of Energy (2011) Re-assessing green building performance: A post occupancy evaluation of 22 buildings.

2. Booz Allen Hamilton Inc and the US Green Building Council (2015) 2015 Green building economic impact study.

3. IPCC (2013) Climate Change 2013: The physical science basis, Contribution of Working Group I to the Fifth Assessment Report of the Intergovernmental Panel on Climate Change, Cambridge University Press, Cambridge, UK
Citation: Snow R, Snow M (2017) Green Building Business is Booming. J Climatol Weather Forecasting 5: e112. doi:10.4172/2332-2594.1000e112

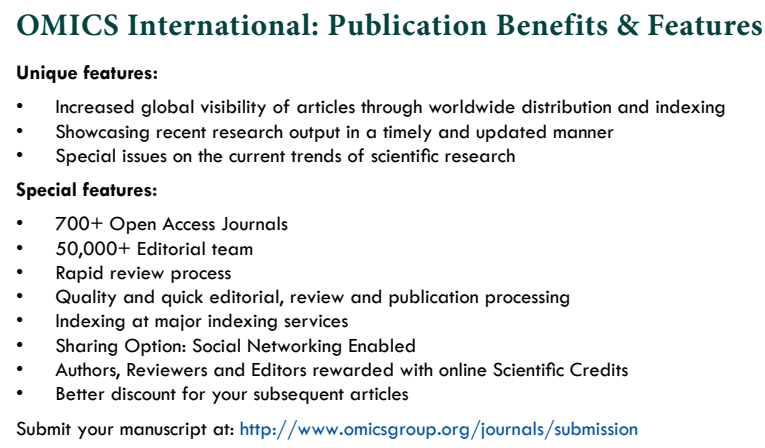

